\title{
Universidade e Escola Básica: uma importante parceria para o aprimoramento da educação científica
}

\author{
University and Elementary School: a important \\ partnership to the improvement of science education
}

\author{
Neusa Maria John Scheid \\ Briseidy Marchesan Soares \\ Maria Lorete Thomas Flores
}

\begin{abstract}
Resumo
O artigo em tela é resultado de um projeto de extensão universitária que tem por finalidade possibilitar a inserção de acadêmicos de um curso de licenciatura em Ciências Biológicas em escolas de educação básica. Durante o projeto, o acadêmico vivencia o cotidiano de uma escola de educação básica participando de uma assessoria didático-científica junto aos professores de Ciências e Biologia. Paralelamente, na universidade participa de atividades de capacitação para essas atividades. Por meio dessa inserção, busca-se promover um maior intercâmbio da universidade com as escolas e discutir subsídios teóricometodológicos que possam contribuir para a melhoria da formação inicial e da prática docente dos professores já em exercício. Entende-se essa parceria entre universidade e escola básica como crucial para o aprimoramento da educação científica escolar.
\end{abstract}

Palavras-chave: formação de professores, educação científica, educação básica.

\begin{abstract}
The article in question is the result of a university extension project which aims to allow the insertion of academics of degree in biological sciences in schools of elementary education. During the project, the academic experience everyday life in a school of basic education participating in an educational and scientific advisor with the teachers of Science and Biology. In addition, he participates - in the university on activities of training for such activities. Through this integration, seeks to promote a greater exchange of the university with schools and discuss the theoretical and methodological subsidies that may contribute to improving the training and teaching practice of teachers already in office. It is understood that partnership between the university and elementary school as crucial to the improvement of science education at school.
\end{abstract}

Keywords: Teachers' education, scientific education, basic education. 


\section{Introdução}

Nos cursos de formação inicial de professores da área das Ciências Naturais percebe-se uma saudável preocupação com a inserção desses futuros profissionais no cotidiano da escola básica. Por sua vez, no dia-a-dia de uma escola de educação básica, constantemente, surge a preocupação com a qualidade da educação científica que resulta de suas atividades inerentes a sua função como instituição educativa. Diversos instrumentos de avaliação são utilizados para mensurar essa qualidade. No final de 2007 foi divulgado o resultado do Programa Internacional de Avaliação de Alunos (PISA) que contou com a participação de estudantes brasileiros. O Brasil ficou nas últimas posições, o que indica que há graves deficiências no seu sistema educativo. Segundo o professor Nélio Bizzo (2008), a origem do problema pode estar na forma como o ensino, principalmente o de ciências, é conduzido. Ele relata que a maioria dos alunos não é estimulada a pensar a respeito das questões que lhes são colocadas, mas, sim, apenas decoram conceitos, que, acabam esquecidos, por não Ihes parecerem muito úteis. Sem contar a visão inadequada de ciência, como uma verdade absoluta e inquestionável, apresentada por muitas pessoas envolvidas nesse contexto.

Diante desses resultados, pode-se inferir que um dos fatores que podem estar contribuindo para esse quadro está relacionado com a formação inicial dos professores dessa área de ensino, com repercussões também sobre a formação continuada.

Adams e Tillotson (1995) relatam a preocupação com a preparação do professor de ciências que, desde décadas anteriores, já era reconhecida mundialmente como crítica no momento das reformas educacionais. Cunha e Krasilchik (2000) reforçam que no Brasil, o tema da formação do professor de ciências constantemente está na pauta de discussões que envolvem a questão da melhoria do ensino de ciência, evidenciada pelo crescente interesse em pesquisa com a formação inicial e continuada de professores.

Os cursos de formação de professores, tanto aqueles destinados à sua preparação formação inicial, como aqueles voltados para a sua atualização - formação continuada, vêm sendo considerados insatisfatórios. A não integração da Universidade com as escolas de Ensino Fundamental e Médio, bem como a falta de interação entre os estudos teóricos e a prática docente têm sido apontadas por pesquisadores em Educação em Ciência, no mundo todo, como algumas das causas, entre outras, dessa ineficiência (CUNHA; KRASILCHIK, 2000).

Além do compromisso com a formação inicial, cabe à Universidade o papel da formação continuada dos docentes que já atuam no ensino de ciências. Justifica-se esse compromisso, pois, de uma ou outra forma, esses docentes servirão de "guias" para os acadêmicos quando iniciarem suas práticas profissionais, no momento em que estarão realizando sua transição de estudantes para professores e criando sua identidade profissional. 
Acredita-se que, quanto mais cedo os alunos graduandos de um curso de licenciatura em Ciências Biológicas realizarem sua inserção nas escolas onde atuarão como profissionais no futuro, mais e melhores contribuições serão proporcionadas ao processo ensino-aprendizagem. Concomitantemente, os professores já inseridos na atividade docente, com os quais haverá intercâmbio de saberes, serão estimulados a (re)pensar sua prática pedagógica, o que representará, também, contribuições para a dinamização do processo ensino-aprendizagem em ciências.

\section{Considerações acerca da complexidade}

\section{da formação de professores de Ciências}

É impossível dissociar qualidade de ensino de ciências e formação de professores de ciências, pois são questões que estão intimamente ligadas. A formação teórica e prática do professor poderá contribuir para melhorar a qualidade do ensino se ocorrer de forma continuada. Há algumas décadas, acreditava-se que, uma vez terminada a graduação, o profissional estaria apto com competência suficiente para atuar na sua área o resto da vida. Hoje a realidade é diferente, principalmente para o profissional docente. Este deve estar consciente de que sua formação deverá ser permanente e integrada no seu dia-a-dia nas escolas (ROBERTO, 2007).

Conforme estabelecida nos artigos 22, 27, 32, 35 e 36 da LDBEN (Lei de Diretrizes e Bases da Educação Brasileira, Lei no. 9394/96) e nas Diretrizes Curriculares Nacionais da educação básica: é imprescindível ao professor que se prepara para lecionar na educação básica demonstrar que desenvolveu ou tenha oportunidade de desenvolver, de modo sólido e pleno, as competências previstas para os egressos da educação básica. Essa é uma condição mínima, indispensável, para qualificá-lo como capaz de lecionar na Educação Infantil, no Ensino Fundamental ou no Ensino Médio. Muitos dos jovens que hoje saem da educação básica e ingressam no ensino superior não satisfazem essa condição mínima. É preciso que a formação docente propicie a esses jovens a oportunidade de refazer o percurso de aprendizagem que não foi satisfatoriamente percorrido na educação básica para fazer deles bons professores que, no futuro, contribuam para a melhoria da qualidade da própria educação básica (BRASIL, 1997, 2000).

A formação de um profissional qualificado para exercer plenamente as atribuições que são legalmente conferidas ao professor exige uma completa renovação do modelo de formação inicial e continuada, superando as deficiências e a desarticulação que tem sido reiteradamente apontada no modelo atual e aproveitando as contribuições de experiências exitosas. Nunca se discutiu tanto no Brasil a política de formação de professores como nos últimos anos e nunca contamos com condições institucionais tão favoráveis para desencadear as rupturas e mudanças 
necessárias. O novo modelo de formação inicial e continuada deve preparar profissionais aptos para desempenharem as atividades de magistério num mundo em rápida transformação e, acima de tudo, comprometidos com o direito de aprender (MARANHÃO, 2000)

Há consenso entre educadores das mais diversas correntes pedagógicas de que o professor desempenha um papel insubstituível para o sucesso da aprendizagem dos alunos. Por isso, é amplamente reconhecido que só a presença, em cada sala de aula, de um professor bem preparado, motivado e comprometido com a aprendizagem dos alunos pode dar sustentação, a médio e longo prazo, às reformas da educação básica e garantir a qualidade do ensino (MARANHÃO, 2000).

A formação de professores como preparação profissional passa a ter papel crucial, no atual contexto, agora para possibilitar que possam experimentar, em seu próprio processo de aprendizagem, o desenvolvimento de competências necessárias para atuar nesse novo cenário, reconhecendo-a como parte de uma trajetória de formação continuada ao longo da vida (LIMA; DORST; KRAHE, 2005).

Em relação à formação inicial de professores, Mello (2000) cita como problema, o fato da localização institucional da maioria das licenciaturas na estrutura do ensino superior, e particularmente das universidades, criar um divórcio entre a aquisição de conhecimentos nas áreas de conteúdos específicos e a constituição de competências para ensinar esses conteúdos a crianças, adolescentes ou adultos. O único aspirante ao magistério que ingressa no ensino superior com opção clara pelo ofício de ensinar é o aluno dos cursos de pedagogia. A esses, na maior parte dos cursos, não é oferecida a oportunidade de seguir aprendendo os conteúdos ou objetos de ensino que deverá ensinar no futuro. Aprende-se a prática do ensino, mas não sua substância. Os demais ingressam no ensino superior de formação de professores com a expectativa de serem biólogos, geógrafos, matemáticos, lingüistas, historiadores ou literatos, dificilmente professores de biologia, de geografia, de matemática, de línguas, de história ou de literatura. A maioria dos cursos de graduação é ministrada num contexto institucional distante da preocupação com a educação básica, que não facilita nem mesmo a convivência com pessoas e instituições que conhecem a problemática dessa última. Os professores formadores que atuam nesses cursos, quando estão em instituições de qualidade, são mais preocupados com suas investigações do que com o ensino em geral, e menos interessados ainda no ensino da educação básica.

Mello (2000) sugere que a mudança nos cursos de formação inicial de professores terá de corresponder, em extensão e profundidade, aos princípios que orientam a reforma da educação básica, mantendo com esta sintonia fina. Não se trata de criar modismos, mas de buscar modalidades de organização pedagógica e espaços institucionais que favoreçam a constituição, 
nos futuros professores, das competências docentes que serão requeridas para ensinar e fazer com que os alunos aprendam de acordo com os objetivos e diretrizes pedagógicas traçados para a educação básica.

A mudança na formação inicial do professor deve tomar como eixo principal os saberes relativos à atividade profissional, fundindo e inter-relacionando os saberes das disciplinas, os saberes pedagógicos, os curriculares e/ou didáticos segundo um modelo enraizado, tendo em vista o estudo de experiências e de práticas pedagógicas (FIORENTINI; SOUZA; MELO, 1998).

Os cursos de licenciaturas têm como um dos seus pressupostos, o de instrumentar o futuro professor para que possa exercer sua profissão com competência. É nos cursos de licenciaturas que o futuro professor recebe informações teórico-científicas e formação pedagógica para conduzir seu trabalho docente (CARNICER; ZANON, 2000).

Os professores aprendem sobre como ensinar ciências, não somente durante os anos de licenciatura, mas durante toda sua vida profissional. O desenvolvimento do professor não abrange apenas aspecto profissional, mas também os aspectos pessoais e sociais. Enquanto, o aspecto profissional se refere de algum modo à aprendizagem de novas atividades a serem utilizadas em sala de aula, o aspecto social se refere à reconstrução do conhecimento coletivo sobre o que significa ser um professor de ciências e o aspecto pessoal envolve estar ciente e aceitar a necessidade de mudança, bem como lidar com os sentimentos associados com mudanças (BELL,1998).

O ensino de ciências, na atualidade, se preocupa em investigar novos caminhos e não apenas com a mera descrição de teorias e experiências científicas e com a visão de que o conhecimento é algo que se constrói. As atenções da educação estão hoje basicamente voltadas para a idéia de cidadania e para a formação de professores com novos perfis profissionais, mestres em condições de trabalhar com uma visão interdisciplinar da ciência, própria das múltiplas formas de se conhecer e intervir na sociedade hoje. Neste sentido, as propostas mais adequadas para um ensino de Ciências coerente com tal direcionamento devem favorecer uma aprendizagem comprometida com as dimensões sociais, políticas e econômicas que permeiam as relações entre ciência, tecnologia e sociedade. Trata-se, assim, de orientar o ensino de ciências para uma reflexão mais crítica acerca dos processos de produção do conhecimento científicotecnológico e de suas implicações na sociedade e na qualidade de vida de cada cidadão. É preciso preparar os cidadãos para que sejam capazes de participar, de alguma maneira, das decisões que se tomam nesse campo, já que, em geral, são disposições que, mais cedo ou mais tarde, terminam por afetar a vida de todos. Essa participação deverá ter como base o conhecimento científico adquirido na escola e a análise pertinente das informações recebidas sobre os avanços da ciência e da tecnologia (SANTOS, 2006). 
Os atuais avanços da ciência e tecnologia têm provocado profundas transformações no comportamento social, nas formas de comunicação, nos processos produtivos, na organização do trabalho e, consequentemente, na formação de recursos humanos. Em decorrência dessas mudanças a sociedade vem exigindo profissionais que, além de competência técnica, apresentem capacidade de engajamento, iniciativa e tomada de decisões (MARICATO; CORAZZA-NUNES; GIANOTTO, 2000). Considerando essa nova característica da sociedade, destaca-se que o papel fundamental da escola é: preparar gerentes da informação e não meros acumuladores de dados, pois o gerente é o indivíduo capaz de equacionar problemas do ponto de vista técnico, social, político e ético, tomando decisões com segurança e pertinência (MORETTO,1999).

Diante dessas exigências da sociedade com relação à escola, faz-se necessário resgatar o papel do professor como agente histórico de transformação, mediador na formação de cidadãos críticos e conscientes de seu papel na construção de uma sociedade mais justa, livre, solidária e capaz de definir seu próprio futuro (MARICATO; CORAZZA-NUNES; GIANOTTO, 2000).

Concordamos com Selles (2002) quando afirma que a formação de um professor é um processo contínuo. $\mathrm{O}$ momento de seu ingresso ao curso de formação inicial é apenas um marco numa trajetória de crescimento onde, somados aos constituintes da história de vida deste indivíduo, irão conjugar-se conhecimentos de uma dada área específica, teorias pedagógicas e elementos práticos oriundos da atividade docente e, em conjunto, formam a base sobre a qual a profissão irá se alicerçar.

Entretanto, não se pode desconsiderar que há uma limitação inerente à própria natureza da formação inicial que leva a indagar até que ponto o recém-egresso, a despeito da qualificação outorgada pela universidade, seria, efetivamente, um professor. Considerando-se, entretanto, que as atividades docentes, como todos os processos sociais, são marcadas pela diversidade e caracterizadas por uma dinâmica não determinística, seria impossível antecipar a experiência pedagógica aos futuros professores nos cursos de licenciatura (SELLES, 2002).

Para Barcelos (2000) os licenciados, durante a formação inicial precisam iniciar-se no processo de reformulação e ressignificação de conhecimentos para a construção do "Saber da ação pedagógica" a partir da conexão com suas experiências e com as de outras pessoas.

De acordo com Selles (2002) parece ser consensual, para diversos autores, que seja oferecido para o professor em exercício um programa de formação continuada que seja capaz de funcionar, não apenas como oportunidade de atualização de conhecimentos, face às inúmeras inovações que surgem, mas também como elemento "decodificador" das práticas vivenciadas no dia-a-dia da sala de aula. Paralelamente, o desenvolvimento profissional situa-se, com explícita complexidade, para além do campo das aquisições e renovações pedagógicas. 


\section{Aproximando universidade e escola:}

\section{relato de um projeto de extensão}

Diante desse contexto, o departamento de Ciências Biológicas da Universidade Regional Integrada do Alto Uruguai e das Missões - URI - campus de Santo Ângelo, elaborou o projeto homônimo desse artigo que tem por finalidade possibilitar a inserção dos acadêmicos de Ciências Biológicas nas escolas de educação básica como forma de promover um maior intercâmbio da universidade com as escolas e discutir subsídios teórico-metodológicos que possam contribuir para a melhoria da formação inicial e da prática docente.

O projeto também tem por finalidade se ocupar de questões didático-pedagógicas e epistemológicas, considerando que as escolas precisam apresentar aos jovens uma visão adequada do que constitui a ciência e de qual é sua importância para o cotidiano do cidadão. Ela não pode ficar restrita aos conteúdos elencados nos programas desenvolvidos em sala de aula. Os alunos devem ser estimulados a pensar, a questionar e a investigar, a partir de problemas que se colocam no dia-a-dia. Para isso, o professor, precisa estar capacitado e atualizado continuamente, não apenas nos conteúdos específicos, mas também nas questões pedagógicas e epistemológicas mais amplas, no caso particular do conhecimento científico.

O projeto está sendo desenvolvido em três escolas de educação básica , da rede estadual de ensino do Estado do Rio Grande do Sul, pertencentes a 14ä. CRE - Coordenadoria Regional de Educação. Essas escolas foram selecionadas conforme critérios estabelecidos pelos coordenadores do projeto. Os critérios de participação dos professores em exercício na escola nos projetos de formação continuada coordenados pela universidade e a disponiblidade da escola em acolher os acadêmicos durante os estágios foram decisivos para e escolha. O número de escolas participantes é determinado pelo número de bolsas de extensão disponíveis para o projeto.

Após a apresentação do projeto e garantia do comprometimento de gestores e professores da área de ciências em cada escola selecionada, realizou-se um diagnóstico das dificuldades encontradas pelos professores ao ensinar Ciências e Biologia. Esse diagnóstico foi realizado por meio de entrevistas semiestruturadas, além de observação in loco das condições do laboratório da escola.

Os resultados encontrados foram determinantes na elaboração da proposta de assessoria didático-científica, diferenciada para cada escola, de modo a atender às necessidades pedagógicas de cada uma. Essas propostas, foram elaboradas pelos acadêmicos na universidade e sob a supervisão de uma professora orientadora. Destaca-se, no entanto, que elas somente foram colocadas em execução após submetidas à apreciação dos professores envolvidos e incorporadas as modificações por eles sugeridas. 
Durante o desenvolvimento do projeto o acadêmico permanece três turnos na escola básica e dois turnos na universidade. Na escola, o acadêmico realiza atividades de assessoria didático-científica, dando suporte aos professores na realização de aulas práticas em laboratório e em trabalhos de saída de campo, bem como na organização de coleções didáticas de Zoologia, Botânica e áreas afins. Na universidade, comparece para receber orientação, fazer pesquisa e preparar material didático-pedagógico.

Os professores em exercício na escola básica são convidados a participar de reuniões para discutir os problemas reais vivenciados na sua rotina didática. Essas reuniões são realizadas na escola ou na universidade. Partindo desta discussão são abordados temas diversos, inclusive alguns que visam a aumentar a auto-estima do professor e ajudá-lo a (re) descobrir sua competência profissional.

Segundo Selles (2002), deve-se proporcionar ao professor que reconheça que o aprendizado se constrói numa via de "mão-dupla". Ou seja, não apenas o conhecimento acadêmico produzido na universidade tem a contribuir para com os professores, como, igualmente, a vivência oriunda do trabalho diário na escola fornece importante contribuição a ser explorada teoricamente. Esses últimos, segundo Gauthier et al. (1998), são os saberes da experiência.

Há uma boa aceitação do projeto tanto pelos acadêmicos do curso de licenciatura, quanto dos gestores e professores das escolas envolvidas. A avaliação contínua do desenvolvimento do projeto, por meio da observação in loco nas escolas e a análise das discussões nas reuniões, tem possibilitado a percepção de que os professores estão encontrando nos acadêmicos um apoio didático-científico, seja como monitores para auxiliar na realização das atividades diferenciadas nas aulas de Ciências e Biologia, seja como mediadores na busca de atualização de conhecimentos científicos.

Por outro lado, a inserção de acadêmicos na escola de educação básica é de grande valia na sua formação inicial, pois ao entrarem em contato com a realidade escolar, estão dinamizando sua formação profissionalizante construindo uma postura docente crítica e em constante transformação;

Observa-se que a monitoria tem possibilitado aos acadêmicos incentivar os professores já em exercício a utilizar diversas técnicas de ensino ou modalidades didáticas que são promotoras de melhoria da educação científica. Assim, tem-se percebido que os professores, mais motivados, utilizam modalidades didáticas que permitam associar os conteúdos teóricos tradicionais a temas atuais em aulas expositivas; realizam aulas demonstrativas e promovem discussões por meio de filmes e documentários; realizam uma aprendizagem lúdica por meio da utilização de jogos didáticos; desenvolvem projetos como modo de instigar a pesquisa. 
Tem-se presente que a formação de professores não se esgota no curso de formação inicial, devendo ser pensada, conforme Caldeira (1993), como um processo. Por outro lado, esse processo, como tal, também não se esgota em um projeto como o que vem sendo desenvolvido. É necessário que a formação do professor, tanto a inicial como a em serviço, se construa no cotidiano escolar, na escola, que é um local privilegiado de reflexão pedagógica, ocorrendo sempre de forma constante e contínua.

A aproximação da universidade à escola, contudo, não poderá se resumir apenas na inserção dos acadêmicos nesse ambiente propício para a melhoria da formação de professores. É preciso também, aproximar a escola à universidade, pois é nessa instância que se produz o conhecimento científico em relação à prática pedagógica. É também, a partir da universidade, que se irradia o conhecimento construído nas mais diversas áreas do conhecimento. Em vista disso, criou-se um grupo de estudos (Grupo de Estudos em Educação em Ciências) que se constitui uma possibilidade real de promoção dessa aproximação da escola ao ambiente de excelência na produção de saberes. Por meio do Grupo de Estudos está sendo feito o feedback do projeto. Com o objetivo de levar o professor a discutir questões sobre o ensino com seus pares, com os formadores de professores - docentes da universidade, e com os acadêmicos - professores ainda em constituição, o grupo de estudos é a instância que pode promover o aprimoramento da educação científica escolar.

\section{Considerações finais}

O projeto "Universidade e Escola Básica: uma importante parceria para o aprimoramento da Educação Científica" vem apresentando resultados positivos em, pelo menos, três aspectos a serem considerados. Inicialmente, a inserção de acadêmicos na escola de educação básica é de grande valia para os mesmos, considerando que lhes possibilita entrar em contato com a realidade escolar, dinamizando sua formação profissionalizante inicial construindo uma postura docente crítica em constante transformação; para os professores já em exercício, oportuniza a formação continuada, pois ao interagir com o mundo acadêmico, aperfeiçoam sua atuação no ensino; e para a escola e a sociedade, representa uma alternativa de melhoria da educação que poderá garantir a formação de cidadãos com uma educação científica adequada aos desafios atuais.

Se os conhecimentos constituídos pelos futuros professores na universidade em sua trajetória pré-profissional vão influenciar na sua atuação docente (ARAÚJO Jr.; AMARAL, 2006), é muito provável que as experiências dos acadêmicos inseridos no projeto, exerçam influências positivas significativas em suas trajetórias profissionais. Em longo prazo, o que se espera como resultado é que a promoção dessa experiência formativa de aprendizagem profissional inicial dos 
acadêmicos do curso de Ciências Biológicas thes oportunize estruturar os primeiros passos como futuros professores em direção a uma postura reflexiva, crítica, aberta às mudanças e em permanente evolução profissional, de forma a contribuir para o aprimoramento da educação científica.

\section{Bibliografia}

ADAMS, P. E.; TILLOTSON, J. W. Why research in the service of science teacher education in needed. Jounal of Research in Science teaching. v. 32, n. 5, p. 441-443, 1995.

ARAÚJO Jr, Carlos; AMARAL, Luiz Henrique (organizadores). Ensino de Ciências e Matemática: Tópicos em Ensino e pesquisa. São Paulo: Andross, 2006.

BARCELOS, N. N. S. Saberes docentes na formação do professor reflexivo de ciências e biologia.

Caderno de textos da V Escola de verão para professores de prática de ensino de física, química, biologia e áreas afins. Bauru-SP, 2000.

BELL, B. Teacher Developmente in Science Education. The Subject Matter Knowledger of Preservice Science Teachers. In: B. J. Fraser and K. G. Tobin (Eds.), International Handbook of Science Education. Inside the black box: Raising standard through classroom assessment. Publicado pelo King's College of London, 1998.

BIZZO, N. Educação - Nota baixa em ciências. Boletim Ciência Hoje (online), n. 134. 2008.

BRASIL. Parâmetros Curriculares Nacionais: Introdução (10 e 20 ciclos). Vol. 1. Secretaria de Educação Fundamental. - Brasília: MEC/SEF, 1997.

BRASIL. Parâmetros Curriculares Nacionais: Ciências Naturais (1ํ e 2o ciclos). Vol. 4. Secretaria de Educação Fundamental. 2a ed. Rio de Janeiro: MEC/SEF, DP\&A, 2000.

CALDEIRA, A. M. S. La prática docente cotidiana de una maestra y el processo de apropriación y construcción de su saber. Barcelona: Universidade de Barcelona, 1993. 347 p. (Tese de doutorado).

CARNICER, W. C. F.; ZANON, A. M.a. A formação do professor e a prática de ensino de ciências e biologia. Caderno de textos da V Escola de verão para professores de prática de ensino de física, química, biologia e áreas afins. Bauru, SP, 2000.

CUNHA, A. M. O; KRASILCHILK, M. A formação continuada de professores de ciências: percepções a partir de uma experiência, trabalho apresentado na 29a REUNIÃO ANUAL ANPEd [seção Formação de Professores], Caxambu, 2000. 
FIORENTINI, D.; SOUZA, A. J.; MELO, G. F. A. Saberes docentes: um desafio para acadêmicos e práticos. In: Geraldi, C. M. G., Fiorentini, D., Pereira, E. M. (org.) Cartografia do Trabalho Docente: professor(a)-pesquisador(a). Campinas: ALB e Mercado de Letras, 1998.

GAUTHIER, C.; MARTINEAU, S.; DESBIENS, J. F.; MALO, A.; SIMARD, D. Por uma teoria da pedagogia: pesquisas contemporâneas sobre o saber docente. Trad. Francisco Pereira. ljuí: Unijuí, 1998.

MARANHÃO, E.A. A Qualidade no Trabalho Docente. Anais: Seminário Escola Jovem: um novo olhar sobre o ensino médio. Brasília, 2000.

MARICATO, F. E.; CORAZZA-NUNES, M. a J.; GIANOTTO, D. E. P. Reflexões sobre a formação do professor de ciências e biologia. Caderno de textos da V Escola de verão para professores de prática de ensino de física, química, biologia e áreas afins. Bauru, SP, 2000.

MELLO, G. N. Formação Inicial de Professores para a Educação Básica: uma (re)visão radical. São Paulo em Perspectiva, 14(1) 2000.

MORETTO, V. P. Construtivismo: a produção do conhecimento em aula. Rio de Janeiro: DP \& A, 1999.

ROBERTO, L. O. O professor, sua formação e sua prática, set/2007.

http://www.centrorefeducacional.com.br/artleit.htm. Acesso em 16/04/08.

SANTOS, P. R. O Ensino de Ciências e a Idéia de Cidadania. Mirandum. Ano X - n. 17. Universidade do Porto - Faculdade de Direito Instituto Jurídico Interdisciplinar, 2006.

SELLES, S. E. Formação continuada e desenvolvimento profissional de professores de ciências: anotações de um projeto. ENSAIO - Pesquisa em Educação em Ciências, v. 2, n. 2, Universidade Federal Fluminense, 2002.

Neusa Maria John Scheid: Doutora em Educação Científica e Tecnológica, professora da Universidade Regional Integrada do Alto Uruguai e das Missões, programa de Mestrado em ensino Científico e Tecnológico.

Briseidy Marchesan Soares: Mestre em Biociências, professora da Universidade Regional Integrada do Alto Uruguai e das Missões.

Maria Lorete Thomas Flores: Mestre em Biologia, professora da Universidade Regional Integrada do Alto Uruguai e das Missões. 